\title{
A phase $1 /$ II study of irinotecan when added to 5-fluorouracil and leucovorin and pelvic radiation in locally advanced rectal cancer: a Colorectal Clinical Oncology Group Study
}

\author{
R Glynne-Jones*, , S Falk², TS Maughan ${ }^{3}$, HM Meadows ${ }^{4}$ and D Sebag-Montefiore ${ }^{5}$ \\ 'Mount Vernon Cancer Centre, Mount Vernon Hospital, Rickmansworth Road, Northwood, Middlesex HA6 2RN, UK; '² Bristol Haematology and Oncology \\ Centre, Bristol Royal Infirmary, Horefield Road, Bristol BS2 8ED, UK; ${ }^{3}$ Department of Clinical Oncology and Palliative Medicine, School of Medicine, \\ Cardiff University at Velindre Hospital, Whitchurch, Cardiff CF4 7XL, UK; ${ }^{4}$ Cancer Research UK \& UCL Cancer Trials Centre, 90 Tottenham Court Road, \\ London, WIT 4TJ, UK; ${ }^{5}$ Leeds Cancer Centre, Cookridge Hospital, Hospital Lane, Cookridge, West Yorkshire LSI6 6QB, UK
}

The objective of this study was to evaluate the maximum tolerated dose (MTD) and recommended dose of irinotecan administered as a 5-day schedule synchronously with 5-fluorouracil (5FU), leucovorin (LV) and preoperative pelvic radiation (45 Gy) for primary borderline/unresectable, locally advanced rectal cancer. The study used escalating doses of intravenous irinotecan $(6,8,10,12,14,16$, I 8 , and $\left.20 \mathrm{mg} \mathrm{m}^{-2}\right)$ administered on days I -5 and $29-33$ followed by low dose LV $\left(20 \mathrm{mg} \mathrm{m}^{-2}\right)$ and $5 \mathrm{FU}\left(350 \mathrm{mg} \mathrm{m}^{-2}\right.$ over I h) in sequential cohorts. Preoperative pelvic radiotherapy using a three- or four-field technique and megavoltage photons comprised $45 \mathrm{~Gy}$ given in 25 fractions, $1.8 \mathrm{~Gy}$ per fraction. Surgery in the form of mesorectal excision was performed 6-10 weeks later. Histopathological examination of the resected specimen was performed according to techniques of Quirke, and compared with clinical staging. A distance of $1 \mathrm{~mm}$ or less between the peripheral extent of the tumour and the radial resection margin defined an involved circumferential resection margin (CRM). The MTD was determined as the dose causing more than a third of patients to have a dose-limiting toxicity (DLT) defined as specific grade 3 or 4 toxicities. Once the MTD was reached, a further 14 patients were treated at the dose level below the MTD. In total, 57 patients received irinotecan at the eight dose levels. The final cohort reached DLT after only four patients had been enrolled. The median age was 62 years (range 26-75), 37 male and 20 female subjects. The MTD of irinotecan in this schedule was $20 \mathrm{mg} \mathrm{m}^{-2}$ when three out of four patients experienced DLT. Dose limiting grade 3 or 4 diarrhoea was reported in seven out of 57 patients, three at the $20 \mathrm{mg} \mathrm{m}^{-2}$ dose level. Serious haematological toxicity (grade 3) was minimal and reported in only three patients; one grade 3 neutropaenia, one grade 4 neutropaenia and one grade 3 febrile neutropaenia and anaemia. Compliance was good with 93 and 89\% of patients completing radiotherapy and chemotherapy, respectively. The remaining patients had only minor deviations from protocol therapy. Eight patients did not proceed to surgery, in six cases because they remained unresectable or had developed metastatic disease, one patient was unfit for surgery and one died as a result of complications from radiotherapy. Forty-nine patients underwent a potentially curative surgical resection. Histopathological examination of the resected specimen demonstrated PCR 12 out of 49 (24\%) and 12 out of 57 (21\%) overall. A histologically confirmed clear circumferential resection margin (CRM) was achieved in 39 out of 49 (80\%) of those resected, and 39 out of 57 (68\%) overall. In conclusion, MTD with this scheduled regimen of irinotecan is $20 \mathrm{mg} \mathrm{m}^{-2}$ (days I-5 and 29-33). The acceptable toxicity and compliance at $18 \mathrm{mg} \mathrm{m}^{-2}$ recommend testing this dose in future phase III studies. The tumour downstaging and complete resection rates (negative CRM) are encouragingly high for this very locally advanced group.

British Journal of Cancer (2007) 96, 55। -558. doi:I 0.1038/sj.bjc.6603570 www.bjcancer.com

Published online 30 January 2007

(c) 2007 Cancer Research UK

Keywords: 5-fluorouracil; irinotecan; locally advanced rectal cancer; preoperative chemoradiation

A curative surgical resection remains the most important component of the modern multimodality management of rectal cancer. However, randomised controlled trials (Swedish Rectal Cancer Trial, 1997; Kapiteijn et al, 2001; Sauer et al, 2004) and two meta-analyses (Cammà et al, 2000; Colorectal Cancer Collaborative Group, 2001) have demonstrated that in clinically resectable rectal

*Correspondence: Dr R Glynne-Jones; E-mail: rob.glynnejones@nhs.net Received 4 October 2006; revised 30 November 2006; accepted I December 2006; published online 30 January 2007 cancer, preoperative adjuvant radiation or chemoradiation can reduce the rate of locoregional recurrence, although its impact on overall survival is less clear.

Recent advances which have contributed to an improved outcome in rectal cancer include a more radical surgical technique incorporating mesorectal excision (TME) (Enker et al, 1995; Heald et al, 1998) and a more accurate histopathological examination of the resected specimen reporting the proximity of microscopic tumour to the circumferential resection margin (CRM) (Quirke et al, 1986). Individual surgical series, a population-based audit (Wibe et al, 2002) and evidence from a randomised controlled trial (Nagtegaal et al, 2002) all demonstrate lower rates of local 
recurrence following TME compared with the previous randomised trials that included a surgery alone arm. In addition, involvement of the circumferential resection margin is associated with a significantly increased risk of both local recurrence and also metastatic disease.

Preoperative chemoradiation (CRT) is increasingly used in patients with more locally advanced, borderline and unresectable rectal cancer, despite the fact that there are few trials in the modern era that have compared preoperative CRT with radiation alone (Frykholm et al, 2001). The aims of treatment are to reduce the extent of the primary tumour to allow macroscopic removal to take place, to treat potential microscopic disease close to or beyond the mesorectal fascia and if present also to treat micrometastatic disease outside the radiation fields. Most current CRT schedules combine pelvic radiation with either continuous infusion of 5-fluorouracil (5FU), or 5FU modulated by LV. Mature results from the EORTC 22921 and FFCD 9203 trials of operable T3/T4 rectal cancer have recently demonstrated a convincing reduction in locoregional failure when a CRT regimen of 5FU and $\mathrm{LV}$ is added to $45 \mathrm{~Gy}$ of pelvic radiation over radiotherapy alone (Bosset et al, 2005a,b; Gerard et al, 2005). As the EORTC 22921 and FFCD 9203 trials used daily 5FU LV based CRT schedules, at the time the present study was designed, it was a logical step to develop preoperative radiation schedules that incorporated the addition of irinotecan to the same regimen. The choice of the $5 \mathrm{FU}$ LV regimen required the 5 -day schedule of irinotecan to be given in weeks 1 and 5 to ensure concomitant administration.

Preclinical studies have demonstrated irinotecan to be a potent radio-sensitising agent in human lung tumour xenografts (Tamura et al, 1997) and colorectal cancer (Wang et al, 1996; Omura et al, 1997; Chen et al, 1999), even under hypoxic conditions, which normally render tumours radio-resistant (Boscia et al, 1993). The mechanism of this interaction may reflect the attachment of the DNA-topoisomerase I adducts at sites of DNA single-strand breaks, or radiation-induced synchronization of the tumour cell population in the $S$ phase of the cell cycle, where cells are more sensitive to irinotecan chemotherapy (Falk and Smith, 1992). Furthermore, the cytotoxic effects of camptothecins are highly schedule dependent. Both 5FU (Byfield et al, 1982) and irinotecan (Kirichenko et al, 1997) are radiation sensitisers, which appear both dose and schedule dependent according to preclinical models. In the preclinical setting, more frequent fractionated schedules appear more effective (Kirichenko and Rich, 1999). This hypothesis, to some extent, is logical if one considers that the half-life of SN38 (the metabolite of the camptothecins) is long, and a daily intravenous schedule can result in a relatively steady level. Radiation sensitisation occurs during or after irradiation (Omura et al, 1997). Hence, we have used a protracted low-dose schedule of irinotecan in the present study.
The rationale behind the use of these two drugs combined with radiotherapy lies in the evidence from phase III trials in metastatic colorectal cancer, which have demonstrated statistically significant improvements in overall response rate and median time to progression and overall survival when the topoisomerase-I inhibitor irinotecan is added to a combination of $5 \mathrm{FU}$ and $\mathrm{LV}$ (Douillard et al, 2000; Saltz et al, 2000). It is also recognised that $20-40 \%$ of rectal cancer patients continue to develop distant metastases and die despite the optimal use of TME and a very low risk of local recurrence (Kapiteijn et al, 2001; Sauer et al, 2004).

Also a recent review of phase II and III trials of preoperative chemoradiotherapy (Hartley et al, 2005) showed that on multivariate analysis only the mode of delivery of 5FU (infusion rather than bolus), the use of a second drug in addition to 5FU and the total radiation dose were associated with a higher rate of pathological complete response.

The present study aimed to evaluate the toxicity and efficacy of the addition of a 5-day schedule of irinotecan to a regimen of chemoradiation that uses 5FU and LV daily during the first and fifth weeks of pelvic radiation ( $45 \mathrm{~Gy}$ ) as used in the EORTC 22921 and FFCD 9203 phase III trials (Bosset et al, 2005a, b; Gerard et al, 2005).

\section{PATIENTS AND METHODS}

\section{Study design}

This dose escalation study aimed to increase the dose of irinotecan given on days $1-5$ and 29-33 in successive cohorts when added to a chemoradiation (CRT) regimen consisting of low-dose LV and a short infusion of 5FU administered concurrently with radiation until the maximum tumour dose was reached. All patients received radiotherapy ( $45 \mathrm{~Gy})$ with $\mathrm{LV}\left(20 \mathrm{mg} \mathrm{m}^{-2}\right)$ and $5 \mathrm{FU}\left(350 \mathrm{mg} \mathrm{m}^{-2}\right.$ administered over $1 \mathrm{~h}$ ) on days $1-5$ and 29-33, see Figure 1 . Escalating doses of $2 \mathrm{mg} \mathrm{m}^{-2}$ were given starting at $6 \mathrm{mg} \mathrm{m}^{-2}$ in three patients. Subsequent cohorts consisted of six patients. Irinotecan was administered in $100 \mathrm{ml}$ normal saline or dextrose over $2 \mathrm{~h}$ given on days $1-5$ and $29-33(6,8,10,12,14,16,18$ and $20 \mathrm{mg} \mathrm{m}^{-2}$ ) before the LV and 5FU. Dose-limiting toxicities were defined to include grade 3 or 4 diarrhoea, mucositis, grade 3 or 4 thrombocytopaenia and grade 4 neutropaenia associated with fever or lasting for more than 7 days according to the National Cancer Institute Canada common toxicity criteria revised 1994 definitions. Toxicity was recorded prospectively, weekly up to week 6 and then at week 10.

If Grade III or IV dose-limiting toxicity was observed in two or less patients in a cohort of six, then a further cohort were treated at the next dose level. The maximum tolerated dose (MTD) was defined if three or more of six patients experienced dose-limiting

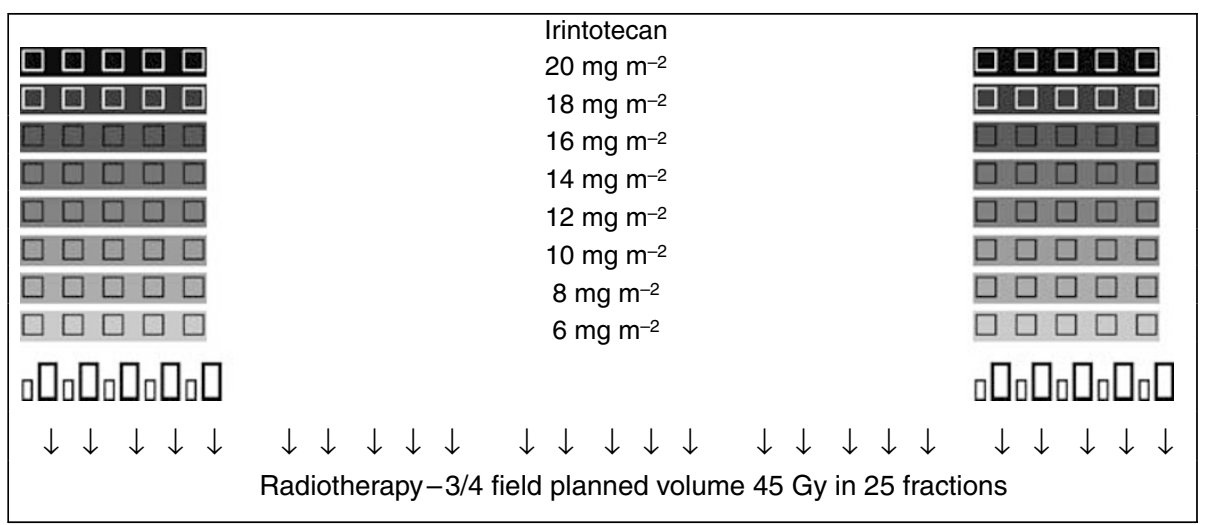

Figure I Chemoradiation schedule. $\square$ Irintotecan at dose levels shown on days I -5 and $29-33$ prior to LV, $5 F U$; $\square$ Leucovorin $20 \mathrm{mg} \mathrm{m}^{-2}$ bolus days I-5, 29-33; प 5FU $350 \mathrm{mg} \mathrm{m}^{-2} 60 \mathrm{~min}$ infusion days I -5, 29-33; $\downarrow$ radiotherapy 1.8 Gy per fraction. 
toxicity (DLT). Once the MTD was defined, the preceding dose level would then be expanded and a total of 20 patients were treated at the recommended dose.

The primary end points of the study were to determine the MTD of irinotecan. Secondary end points included acute toxicity, compliance with the planned doses of chemotherapy and radiotherapy, and efficacy. Efficacy was measured using the following: histopathological complete response rate, complete resection rate and local recurrence rate.

\section{Eligibility criteria}

Eligibility criteria included histologically confirmed adenocarcinoma, WHO performance status $0-2$ and no evidence of metastatic disease using chest X-ray and abdomino-pelvic CT. Acceptable haematological and renal function was required: neutrophils $>1.5 \times 10^{9} 1^{-1}$, platelets $\geqslant 100 \times 10^{9} 1^{-1}$ and serum creatinine $<1.25 \times$ the institutions upper limit of normal range.

Patients with locally advanced, biopsy proven carcinoma of the rectum were included either on the basis of fixity on digital rectal examination (DRE), T4 stage on pelvic CT or when MRI demonstrated a high risk of involvement of the circumferential resection margin. The method used to define locally advanced disease, distance of inferior tumour border to the anal verge $(\mathrm{cm})$ and intended surgical procedure were also recorded.

Patients were excluded from the study because of prior chemotherapy or pelvic radiation, lack of efficient contraception or pregnancy and bowel or cardiac conditions that would deter the safe delivery of 5FU. Patients having six episodes of stool per day or who were incontinent of faeces were also excluded.

\section{Pelvic radiation}

Using information from clinical examination and pelvic MRI, the gross tumour volume (GTV) was defined using a CT planning scan. Alternatively, orthogonal film simulation was performed with opacification of the small bowel using barium sulphate $300 \mathrm{ml}$ with gastrograffin $20 \mathrm{ml}$. To derive a planning target volume (PTV) margins were added to the GTV according to the radiation planning diagrams $(3 \mathrm{~cm}$ laterally and inferiorly, $2 \mathrm{~cm}$ anteriorly and superiorly) included in the protocol with the exception of the posterior border, which was always located on the most posterior aspect of the bony sacrum. Patients were treated prone with a full bladder using either a three- or four-field technique. A total dose of $45 \mathrm{~Gy}$ was delivered to the International Commission on Radiation Units intersection point using 25 daily fractions of $1.8 \mathrm{~Gy}$.

\section{Surgery and histopathology}

Surgery was recommended to take place 6-10 weeks after completion of chemoradiation. Histopathological examination of the resected specimen was performed according the technique described by Birbeck and Quirke (1999). The circumferential resection margin is considered involved, if microscopic tumour (due to any cause) is present at or less than $1 \mathrm{~mm}$ from the circumferential or radial resection margin.

\section{Assessment during and after treatment}

Full blood count, urea creatinine and electrolytes and liver function tests and acute toxicity scores were assessed prospectively on weeks 1-6 and 10. On completion of CRT, follow-up appointments were given at 3, 612, 24 and 36 months to assess tumour recurrence and late toxicity.

For the purposes of this study, local recurrence has been defined in patients who have had a complete macroscopic resection as evidence of either an intraluminal or extraluminal mass below the sacral promontory and biopsy proven adenocarcinoma or CEA abnormal with or without the presence of metastases. Radiological evidence of interval enlargement of the mass (minimum interval of 6 weeks) was required if based on CT scans alone (biopsy negative and CEA normal).

\section{RESULTS}

Between June 2000 and May 2005, a total of 59 patients were recruited from four centres. Two patients were excluded; one patient stopped chemotherapy owing to 5FU-induced chest pain, and the second patient represented a protocol deviation because they received bolus 5FU instead of infusional 5FU. The characteristics of the 57 eligible patients are summarised in Table 1.

\section{Protocol compliance}

Protocol compliance was good, although one patient progressed during treatment and stopped their radiotherapy and chemotherapy early. Radiotherapy was minimally reduced (one fraction not given) in three patients owing to side effects (pain, illness and diarrhoea), all other patients received the full radiotherapy dose. Only five patients failed to receive all planned chemotherapy, which was reduced in four cases due to toxicity; pain (one), diarrhoea (two) and weight loss (one). The remaining patient fainted prior to treatment and that day's chemotherapy treatment was omitted.

The median field size, in all patients, for the posterior/anterior field was $15.2 \mathrm{~cm}$ (range 9.8-20.5) length $\times 14.0 \mathrm{~cm}$ (range 9.918.1) PA width, and for the lateral/oblique fields $15.1 \mathrm{~cm}$ (range 9.8-20.5) height $\times 13.0 \mathrm{~cm}$ (range 9.9-17.7) AP field size on lateral. Forty-nine out of 57 patients proceeded to have radical surgery, with a median interval to surgery of 10 weeks (IQR 7-12 weeks).

\section{Acute toxicity}

The acute grade $3 / 4$ toxicity experienced is summarised for the eight dose levels and the subsequent patients treated in the expanded cohort at $18 \mathrm{mg} \mathrm{m}^{-2}$ in Table 2. During the dose escalation phase, DLT was seen in three out of four patients at $20 \mathrm{mg} \mathrm{m}^{-2}$. In view of this toxicity, the decision was made to stop recruitment to this dose level and to expand the $18 \mathrm{mg} \mathrm{m}^{-2}$ dose level to the planned total of 20 patients.

The most common toxicity was grade 3 diarrhoea, this occurred in seven patients. Haematological toxicity was uncommon with only three patients affected; grade 3 neutropaenia $\left(14 \mathrm{mg} \mathrm{m}^{-2}\right)$, grade 4 neutropaenia $\left(18 \mathrm{mg} \mathrm{m}^{-2}\right)$ and grade 3 febrile neutropaenia

Table I Patient and tumour characteristics

\begin{tabular}{lc}
\hline Characteristic & $\mathbf{n}=\mathbf{5 7}$ \\
\hline Median age (range) & $62(26-75)$ \\
Male: female $0: 1: 2$ & $37: 20$ \\
WHO status $0: 16: 2$ \\
Site of tumour & $39: 23: 18: 31$ \\
$\quad$ Upper:mid: lower & \\
Local extent & 23 \\
Fixed/unresectable & $33^{\mathrm{a}}$ \\
$\quad$ Locally advanced on MRI & 1 \\
\hline Increase chance of sphincter preservation & \\
\hline
\end{tabular}

${ }^{a}$ Includes three patients with partially fixed unresctable disease also. $\mathrm{WHO}=$ World Health Organisation; MRI = magnetic resonance imaging. 
and grade 3 anaemia $\left(8 \mathrm{mg} \mathrm{m}^{-2}\right)$. One patient died 2 weeks after chemoradiation of complications following radiation ileitis.

\section{Response to treatment}

Tumour downstaging was defined by comparing clinical TN stage prior to treatment (as determined by pelvic MRI) with histopathological stage post surgery. Chemoradiation therapy achieved downstaging in 20 out of $49(41 \%)$ of patients. The pathological stages at surgery were ypT0N0 $=12, y \mathrm{yT} 1 \mathrm{NO}=1, \operatorname{ypT0N} 1=1$, урT1N $1=0$, урT2N0 $=7$, урT2N $1=2$, урT3N0 $=14$, урT3N $1=4$, урT3N2 $=2$ and ypT4N0 $=2$, ypT4N1 $=3$, ypT4N2 $=1$. It can be seen that CRT achieved a complete pathological response in 12 out of $49(25 \%)$ of cases who proceeded to surgery (Table 3$)$ and 12 out of $57(21 \%)$ of the whole group. Histopathology also demonstrated microscopic disease only (Tmic) in two out of 49 (4\%) patients, pCR + Tmic in 14 out of $49(29 \%)$, pT0-2 in 20 out of $49(41 \%)$ and histologically confirmed $(>1 \mathrm{~mm})$ clear circumferential resection margins (CRM) in 41 out of $49(84 \%)$ of those resected, and 39 out of $57(68 \%)$ overall.

\section{Surgery}

Of the 57 evaluable patients, eight did not proceed to surgery, in six cases because they remained unresectable (two) or had metastatic disease (four), one patient was unfit for surgery and one died as a result of complications from radiotherapy (Figure 2). All patients had a preliminary clinical assessment by their surgeon

Table 2 Acute toxicity

\begin{tabular}{|c|c|c|c|c|c|c|c|c|c|}
\hline Irintotecan dose $\left(\mathrm{mg} \mathrm{m}^{-2}\right)$ & 6 & 8 & 10 & 12 & 14 & 16 & $18^{a}$ & 20 & All \\
\hline Patients with DLT & 0 & 0 & 2 & 0 & 1 & 0 & 1/- & 3 & 7 \\
\hline Gd 3 neutropaenia & - & - & - & - & 1 & - & $-1-$ & - & 1 \\
\hline Gd 4 neutropaenia & - & - & - & - & - & - & $-/ 1$ & - & 1 \\
\hline Gd 3 febrile neut & - & 1 & - & - & - & - & $-1-$ & - & 1 \\
\hline Gd3 anaemia & - & I & - & - & - & - & $-1-$ & - & I \\
\hline Gd 3 radiation derm & - & - & I & - & - & - & $-1-$ & - & I \\
\hline Gd 4 rash/desq & - & - & - & - & - & - & |/- & - & 1 \\
\hline Gd 3 pain & - & - & - & - & । & - & $-/ 1$ & - & 2 \\
\hline Gd 4 pain & - & - & - & - & - & - & 1/- & - & 1 \\
\hline Gd 3 constipation & - & - & - & - & - & - & -11 & - & । \\
\hline
\end{tabular}

aThe figures in this column indicate the numbers in the initial six patients treated at this dose level followed by the numbers in the expanded group once the MDT was determined. DLT = dose-limiting toxicity.

Table 3 Pathological response

\begin{tabular}{|c|c|c|c|c|c|c|c|c|c|}
\hline Irintotecan dose $\left(\mathrm{mg} \mathrm{m}^{-2}\right)$ & 6 & 8 & 10 & 12 & 14 & 16 & $18^{a}$ & 20 & All (\%) \\
\hline Number operated & 3 & 5 & 6 & 5 & 5 & 5 & $5 / 12$ & 3 & 49/57 (86\%) \\
\hline Tmic & 0 & 0 & 0 & 0 & 0 & 0 & $1 / 0$ & I & 2/49 (4\%) \\
\hline $\mathrm{RO}(-\mathrm{ve} \mathrm{CRM})^{\mathrm{b}}$ & 3 & 3 & 6 & 4 & 5 & 4 & $5 / 8$ & 3 & $4 I / 49(84 \%)$ \\
\hline pT0-2 pNo & 2 & 0 & 3 & 1 & 2 & 1 & $4 / 5$ & 2 & $20 / 49$ (41\%) \\
\hline
\end{tabular}

aThe figures in this column indicate the numbers in the initial six patients treated at this dose level followed by the numbers in the expanded group once the MDT was determined. ${ }^{\text {b }}$-ve CRM $=$ tumour clearance of more than I $\mathrm{mm}$ from circumferential resection margin; $\mathrm{PCR}=$ histopathological complete response; Tmic=microscopic disease only detected in surgical specimen; $C R M=$ circumferential resection margin.

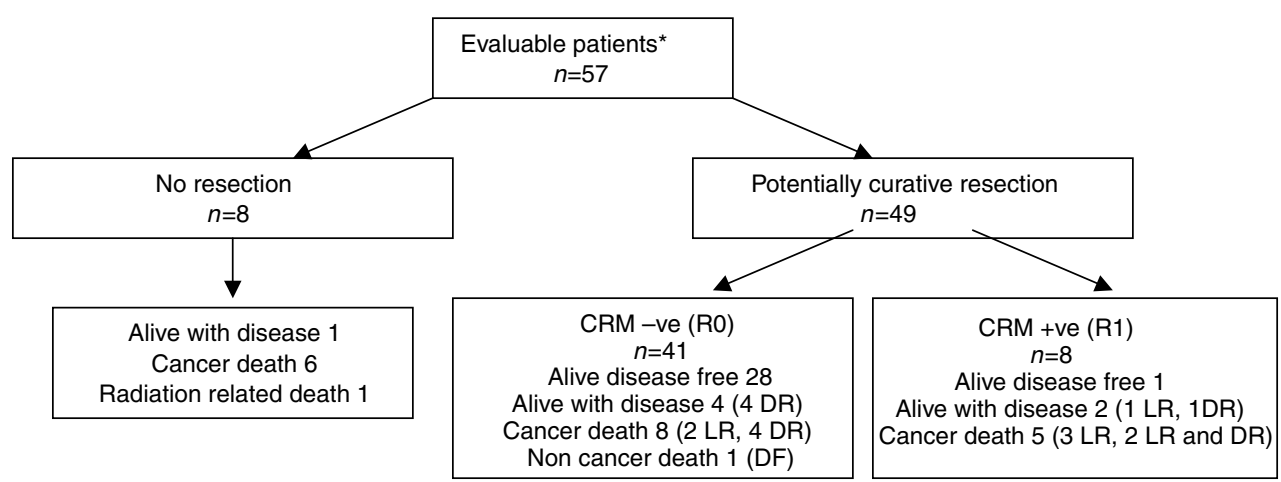

Figure 2 Patient outcome. *Two unassessable patients not included; one patient discontinued chemotherapy owing to chest pain and the other had bolus $5 F U$ on day $\mathrm{I}$. $L R=$ locoregional recurrence, $D R=$ distant recurrence, $D F=$ disease free. 
at entry and were categorised on the basis of height of the cancer from the anal verge as requiring an abdomino-perineal resection (APER), anterior resection (AR) or pelvic clearance (PC).

Of the 49 radical surgical procedures, 24 had an APER, 20 patients an AR, one patient had a low Hartmann's operation. Three female patients required APER and total abdominal hysterectomy and bilateral salpingo-oopherectomy and a male patient had an AR and removal of the bladder and prostate. There were no unexpected postoperative complications or deaths.

\section{Local recurrence and survival}

The median follow-up is 16 months (range 0-60 months) for all patients, 23 patients (40\%) have follow-up of 2 years or more. Thirty-seven of the 57 patients remain alive at the time of writing. Of the 41 patients having complete surgical clearance of tumour (CRM negative), 11 relapsed (one at local and distant sites and 10 distant sites only), of which seven subsequently died of disease (Figure 2 and Table 4). Of the eight incomplete resections (CRM positive), five patients have died, three are alive; two with disease and one currently remains disease free. All but one of the eight patients who were not resected have died, the remaining patient is alive with disease. The disease-free survival (DFS) for the whole group at 3 years is $40 \%$ (95\% CI $24-55 \%$ ) (see Figure 3 ) and $54 \%$ (95\% CI $32-72 \%$ ) for those having had a complete resection.

Of the 20 patients who were downstaged to T0-2 NO, 15 remain alive and disease free, two are alive with distant metastases and three have died of distant disease. Of the 29 patients that were not downstaged (T3/4 NO/1 or T0-2 N1 disease), 10 died due to disease, 18 are alive; four with disease and 14 disease free. The remaining patient died of a myocardial infarction but was disease free at the time of death.

Table 4 Pattern of recurrence following radical resection

\begin{tabular}{|c|c|c|c|c|c|c|c|c|c|}
\hline $\begin{array}{l}\text { Irintotecan dose } \\
\left(\mathrm{mg} \mathrm{m}^{-2}\right)\end{array}$ & 6 & 8 & 10 & 12 & 14 & 16 & 18 & 20 & All \\
\hline Number of patients & 3 & 5 & 6 & 5 & 5 & 5 & $5 / 12$ & 3 & 49 \\
\hline Any disease & 2 & 1 & 3 & 3 & 3 & । & $2 / 4$ & 0 & $19(39 \%)$ \\
\hline Local recurrence & । & I & 0 & 2 & 0 & I & $0 / 3$ & 0 & $8(16 \%)$ \\
\hline Distant metastases & 2 & I & 3 & 1 & 3 & I & $2 / 1$ & 0 & $14(29 \%)$ \\
\hline Cancer death & 2 & I & 2 & 3 & 2 & I & $0 / 2$ & 0 & $13(27 \%)$ \\
\hline Other death & 0 & 0 & 0 & 0 & 0 & $1^{\mathrm{a}}$ & $0 / 0$ & 0 & I (2\%) \\
\hline
\end{tabular}

${ }^{a}$ Cardiac death, no cancer present at time of death.

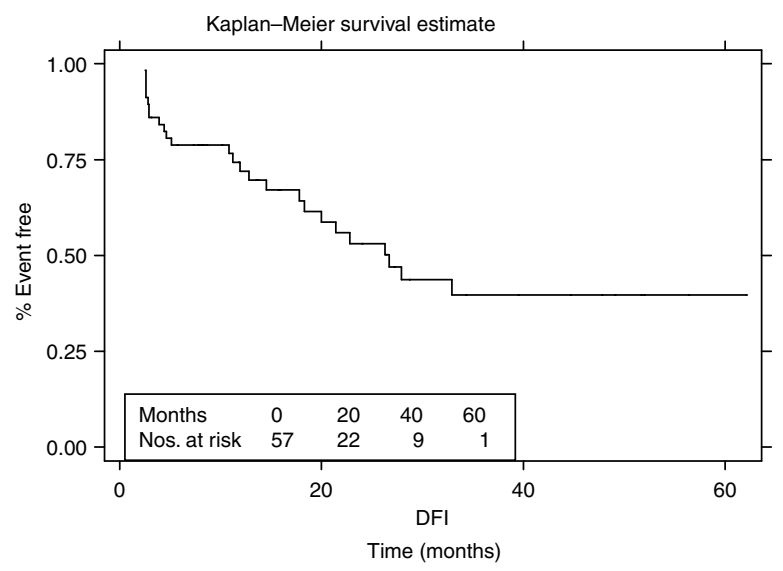

Figure 3 Disease-free survival - all patients.

\section{Late effects}

Severe late effects were uncommon despite the combination of irinotecan and radiotherapy with one patient reporting Grade 3 tenesmus at assessment 12 months after treatment, which later improved to grade $1 / 2$ and had resolved by 4 years.

\section{DISCUSSION}

The primary aim of our current treatment strategy in rectal cancer is to ensure long-term local control, by achieving a curative resection with a clear circumferential resection margin $(>1 \mathrm{~mm})$. However, in many patients with more locally advanced disease, the tumours often remain fixed and unresectable following CRT, and others fail to achieve a histologically curative resection despite neoadjuvant chemoradiation (Mawdsley et al, 2005). A number of phase II studies using 5FU have reported high rates of PCR and $\mathrm{R} 0$ resection even in advanced low rectal cancers. However, the incidence of metastases remains unacceptably high for this group of patients, and does not appear to be influenced by the addition of 5FU over radiation alone (Bosset et al, 2005a, b; Gerard et al, 2005). Intensification of the neoadjuvant strategy has, therefore, been tested in terms of the addition of further cytotoxic agents such as oxaliplatin and irinotecan to standard 5FU-based chemoradiation in an attempt to improve efficacy of downstaging, improve resectability and eradicate potential micrometastases more effectively. Irinotecan appears suitable for inclusion in a neoadjuvant chemoradiation regimen based on the higher response rates observed in randomised trials in metastatic disease (Douillard et al, 2000; Saltz et al, 2000).

The MTD of a scheduled regimen of irinotecan combined with low-dose LV and a 60 min infusion of 5FU with $45 \mathrm{~Gy}$ of pelvic radiotherapy (using relatively large field sizes) given preoperatively in patients with locally advanced rectal cancer has been defined in the present study as $20 \mathrm{mg} \mathrm{m}^{-2}$, days $1-5$ and 29-33. The recommended dose in this setting is $18 \mathrm{mg} \mathrm{m}^{-2}$. This overall total dose of irinotecan $\left(180 \mathrm{mg} \mathrm{m}^{-2}\right)$ is similar to that achieved by others using a schedule of $40-60 \mathrm{mg} \mathrm{m}^{-2}$ weekly during radiotherapy (Levine et al, 2003; Mehta et al, 2003).

Compliance with treatment (93\% radiotherapy and $89 \%$ chemotherapy) in the present study compares favourably with the EORTC 22921 study where compliance to RT was $96 \%$ and to chemotherapy was only $71 \%$ (Bosset et al, 2004). In addition, the rate of grade $3 / 4$ diarrhoea in this study of $12 \%$ is lower than other similar studies with a weekly regimen of irinotecan, which range from 30 to $40 \%$ (Mitchell et al, 2001; Mehta et al, 2003; Klautke et al, 2005).

The eligibility criteria used in this study define a relatively homogeneous group of advanced borderline/unresectable rectal cancer. A total of 23 out of $57(40 \%)$ patients had tumours, which were clinically fixed. The PCR rate of $21 \%$ in the present study is high compared to CRT regimens, which use single agent $5 \mathrm{FU}$ or capecitabine, and is similar to other reported irinotecan CRT regimens (see Table 5).

The histologically confirmed RO (CRM - ve) resection rate of $83 \%$ for those resected and $68 \%$ overall is acceptable for studies in this group of borderline unresectable rectal cancers (Wheeler et al, 2004; Mawdsley et al, 2005; Sebag-Montefiore et al, 2005). In the present study, only two patients had disease, which remained fixed and unresectable following CTRT, and only three patients had partial pelvic clearances. In contrast, the German CAO/ARO/AIO 94 study (Rodel et al, 2003) reported eight out of 31 patients who underwent exenteration or resection of adjacent organs.

Enthusiasm for preoperative chemoradiation in the management of rectal cancer is increasing. The German CAO/ARO/AIO 94 study protocol has convincingly shown improved locoregional control and reductions in acute and late toxicity with preoperative 
Table 5 Preoperative chemoradiation schedules using irinotecan

\begin{tabular}{|c|c|c|c|c|c|c|}
\hline Study/year & $\begin{array}{c}\text { No. of } \\
\text { patients }\end{array}$ & Fluoro-pyrimidine & Irinotecan schedule & $\begin{array}{c}\text { RT } \\
\text { dose } \\
(\mathbf{G y})\end{array}$ & $\begin{array}{c}\text { G3/4 } \\
\text { diarrhoea } \\
(\%)\end{array}$ & $\begin{array}{c}\text { PCR } \\
(\%)\end{array}$ \\
\hline Levine/2003 & 12 & PVI : 5FU $200 \mathrm{mg} \mathrm{m}^{-2}$, daily over 5 weeks & $60 \mathrm{mg} \mathrm{m}^{-2}$ weekly $\times 4$ & 45.0 & 25 & - \\
\hline Mehta/2003 & 32 & PVI: 5 FU $200 \mathrm{mg} \mathrm{m}^{-2}$, days $1-33$ & $50 \mathrm{mg} \mathrm{m}^{-2}$ weekly $\times 4$ & 50.4 & 28 & 38 \\
\hline Mitchell/2003 & 67 & PVI: 5 FU $225 \mathrm{mg} \mathrm{m}^{-2}, 5$ days a week & $50 \mathrm{mg} \mathrm{m}^{-2}$ weekly $\times 4$ & 54.0 & - & 25 \\
\hline Klautke/2005 & 37 & PVI: 5-FU $250 \mathrm{mg} \mathrm{m}^{-2}$, days I -43 & 40 mg weekly $\times 6$ & 50.4 & 32 & 22 \\
\hline Navarro/2006 & 74 & PVI: 5 FU $225 \mathrm{mg} \mathrm{m}^{-2}, 5$ days a week & $50 \mathrm{mg} \mathrm{m}^{-2}$ weekly $\times 5$ & 45.0 & 14 & 14 \\
\hline Descartes/2006 & 57 & 5FU $350 \mathrm{mg} \mathrm{m}^{-2}$, LV $\left(20 \mathrm{mg} \mathrm{m}^{-2}\right.$, days I -5 and $29-33$ & $18 \mathrm{mg} \mathrm{m}^{-2}$ days $\mid-5$ and $29-33$ & 45.0 & 12 & 25 \\
\hline Hofheinz/2005 & 19 & Capecitabine $500 \mathrm{mg} \mathrm{m}^{-2}$, b.i.d., days I-38 & $50 \mathrm{mg} \mathrm{m}^{-2}$ weekly $\times 5$ & 50.4 & 16 & 21 \\
\hline Gollins/2006 & 40 & Capecitabine $650 \mathrm{mg} \mathrm{m}^{-2}$, b.i.d., days I-33 & $60 \mathrm{mg} \mathrm{m}^{-2}$ weekly $\times 4$ & 45.0 & 28 & 25 \\
\hline Klautke/2006a (BJC) & 28 & Capecitabine $750 \mathrm{mg} \mathrm{m}^{-2}$, b.i.d., days $1-43$ & $40 \mathrm{mg}$ weekly $\times 6$ & $50.4+5.4$ & 39 & 14 \\
\hline Klautke/2006b (ASCO) & 20 & Capecitabine $750 \mathrm{mg} \mathrm{m}^{-2}$, b.i.d., days I - 14, 22-35 & $50 \mathrm{mg}$ weekly $\times 4$ & $50.4+5.4$ & 10 & 0 \\
\hline Klautke/2006b (ASCO) & || & Capecitabine $750 \mathrm{mg} \mathrm{m}^{-2}$, b.i.d., days I-14, 22-35 & $60 \mathrm{mg}$ weekly $\times 4$ & $50.4+5.4$ & 9 & 33 \\
\hline Mitchell/2006 & 16 & Capecitabine, MTD not yet reached & $50 \mathrm{mg} \mathrm{m}^{-2}$ weekly $\times 4$ & 50.4 or 54 & - & 23 \\
\hline
\end{tabular}

$\mathrm{PVI}=$ protracted venous infusion; $\mathrm{RT}=$ radiotherapy; $\mathrm{PCR}=$ polymerese chain reaction; $\mathrm{MTD}=$ maximum tolerated dose; $5 F U=5-f l u o r o u r a c i l$.

chemoradiation (Sauer et al, 2004) versus postoperative combined modality treatment for stage II/III resectable rectal cancer.

There is considerable enthusiasm for integrating irinotecan into preoperative combined regimens in rectal cancer, and there have been several reported phase I and II studies (Levine et al, 2003; Mehta et al, 2003; Mitchell et al, 2003; Klautke et al, 2004). Most investigators have explored weekly schedules of irinotecan with infusional 5FU in combination with pelvic radiotherapy (Mitchell et al, 2001; Navarro et al, 2006).

The first study was performed by Mitchell in 2001; as with other studies, high initial PCR rates have not been confirmed with a larger number of patients (Mitchell et al, 2003). An update of this study (Kim et al, 2005) suggests that the pCR rate may be much higher for small tumours $<5 \mathrm{~cm}$. They showed that 11 out of 28 (39\%) of small tumours achieved PCR, compared to only five out of $30(17 \%)$ of tumours larger than $5 \mathrm{~cm}$. Final recommendations from the results of this study were to use $250 \mathrm{mg} \mathrm{m}^{-2}$ per day of $5 \mathrm{FU}$ by continuous infusion, and $50 \mathrm{mg} \mathrm{m}^{-2}$ weekly of irinotecan combined with a radiation dose of $54 \mathrm{~Gy}$. This regimen has been formally compared with a twice-daily hyperfractionated regimen in a randomised phase II study under aegis of the RTOG (RTOG R-0012). UK investigators have explored similar schedules (Levine et $a l, 2003$ ) and produced a recommended dose of $5 \mathrm{FU}$ by continuous infusion $200 \mathrm{mg} \mathrm{m}^{-2}$ and irinotecan $60 \mathrm{mg} \mathrm{m}^{-2}$ weekly with $45 \mathrm{~Gy}$ of radiotherapy.

Further investigators have also combined capecitabine and irinotecan (Kennedy et al, 2004; Becerra et al, 2005; Gollins et al, 2005; Willeke et al, 2005). While preliminary, the current findings indicate that combinations of capecitabine and weekly irinotecan are feasible in this setting. Capecitabine doses can be up to $825 \mathrm{mg} \mathrm{m}^{-2}$ twice daily continuously, while irinotecan can be given up to $60 \mathrm{mg} \mathrm{m}^{-2}$, if only four infusions are administered.

Currently, there is a further ongoing randomised phase II study in the preoperative setting under the aegis of the RTOG (RTOG0247), which compares a combination of irinotecan and capecitabine with a combination of oxaliplatin and capecitabine and higher doses of radiotherapy $(50.4 \mathrm{~Gy})$ than in the present study. Similarly, Klautke et al (2005) also explored $50.4 \mathrm{~Gy}$ with continuous infusion $250 \mathrm{mg} \mathrm{m}^{-2}$ per day and irinotecan $40 \mathrm{mg} \mathrm{m}^{-2}$ weekly, and described an incidence of grade 3 diarrhoea of $35 \%$. This level of toxicity is probably unacceptable for a multicentre phase III study despite a $26 \%$ pathological complete response. An even higher complete response rate has been reported from Mehta et al where again patients were treated with $50.4 \mathrm{~Gy}$ conformal radiotherapy and continuous infusion $5 \mathrm{FU} 200 \mathrm{mg} \mathrm{m}^{-2}$ per day and $50 \mathrm{mg} \mathrm{m}^{-2}$ weekly $\times 4$ of irinotecan. This schedule also provoked a high incidence of grade 3 diarrhoea (28\%), although there was an impressive $37 \%$ pCR rate.
In the preoperative treatment of rectal cancer, it remains to be seen whether the rate of achieving a PCR is an independent prognostic factor for survival. Few studies report long-term local control, late toxicity or the subsequent incidence of metastatic disease. We are continuing to follow this group of patients and hope to provide better information on these issues in the future. Nevertheless, the high levels of pathological complete response with irinotecan need to be confirmed in randomised studies, and the present 5-day schedule would be interesting to assess in combination with capecitabine in phase III randomised trials.

We have yet to determine the optimal irinotecan-based preoperative chemoradiation regimen in rectal cancer. Phase I/II trials confirm that the combination is feasible and highly effective, but many of the studies have shown high levels of grade 3 toxicity - in terms of diarrhoea, see Table 5.

The present study has a number of important differences from the previously described studies (see Table 5). Firstly, the total dose of radiation was fixed at $45 \mathrm{~Gy}$, a total dose that is $10 \%$ lower than many of the other studies. This dose might be expected to be associated with a lower incidence of late complications, and also a lower rate of pathological complete response (Hartley et al, 2005). Secondly, this study formally determined the MTD and recommended dose of irinotecan when added to a validated CRT fluoropyrimidine schedule used in a phase III trial (Bosset et al, $2005 a, b)$. Finally, this study reports outcome data that is based on the circumferential margin status. Now that there is clear evidence that locoregional control is improved by the addition of the $5 \mathrm{FU} / \mathrm{LV}$ regimen used in this study to $45 \mathrm{~Gy}$ of pelvic radiation (Bosset et al, 2005a,b; Gerard et al, 2005), there is a strong rationale for future trials to establish the benefit of the addition of irinotecan.

These data suggest that combination radiochemotherapy leads to improved early histopathological outcome measures. This has the potential to translate into improved long-term outcomes in rectal cancer, both in terms of quality of life and overall survival and will be tested in current and future phase III trials.

\section{CONCLUSION}

The maximum tolerated dose of this scheduled regimen is confirmed as $20 \mathrm{mg} \mathrm{m}^{-2}$, and the recommended dose of irinotecan in BURC is $18 \mathrm{mg} \mathrm{m}^{-2}$ given on days $1-5$ and 29-33 when added to $5 \mathrm{FU} / \mathrm{LV}$ and $45 \mathrm{~Gy}$ of radiation preoperatively. We are continuing to follow this group of patients and hope to provide better information on long-term local control, late toxicity or the subsequent incidence of metastatic disease in the future. 


\section{ACKNOWLEDGEMENTS}

We thank Kathryn McRae and Sara Okumu-Fransche for data management. We also like to acknowledge the contribu- tion of contributing surgeons and research nurses at the contributing institutions. This work was supported by an unrestricted educational grant from Aventis/ Pfizer, UK.

\section{REFERENCES}

Becerra CR, Cho LC, Gregorcyk S, Simmang C, Frenkel EP, Verma UN (2005) A phase I study with irinotecan, capecitabine and radiation therapy for patients with locally advanced or metastatic rectal cancer. Proc Am Soc Clin Oncol GI Symposium (abstract 212)

Birbeck KF, Quirke P (1999) Reporting protocols in colorectal cancer. CPD Bull Cell Pathol 1: 58-64

Boscia RE, Korbut T, Holden SA, Ara G, Teicher BA (1993) Interaction of topoisomerase I inhibitors with radiation in cis-diamminedichloroplatinum (II)-sensitive and -resistant cells in vitro and in the FSAIIC fibrosarcoma in vivo. Int $J$ Cancer 53: $118-123$

Bosset JF, Calais G, Daban A, Berger C, Radosevic-Jelic L, Maingon P, Bardet E, Pierart M, Briffaux A (2004) Preoperative chemoradiotherapy versus preoperative radiotherapy in rectal cancer patients: assessment of acute toxicity and treatment compliance. Report of the 22921 randomised trial conducted by the EORTC Radiotherapy Group. Eur J Cancer 40: 219-224

Bosset JF, Calais G, Mineur L, Maingon P, Radosevic-Jelic L, Daban A, Bardet E, Beny A, Briffaux A, Collette L (2005a) Enhanced tumoricidal effect of chemotherapy with preoperative radiotherapy for rectal cancer: preliminary results - EORTC 22921. J Clin Oncol 23: 5620-5627

Bosset JF, Calais G, Mineur L, Maingon P, Radosevic-Jelic L, Daban A, Bardet E, Beny A, Ollier A, Collette L (2005b) Preoperative radiation (Preop RT) in rectal cancer: effect and timing of additional chemotherapy (CT) 5-year results of the EORTC 22921 trial. Proc Am Soc Clin Oncol 23: 16S (abstract 3505)

Byfield JE, Colaboro-Jones P, Klisak I, Kulhanian F (1982) Pharmacological requirements for obtaining sensitisation of human tumour cells in vitro to combined 5-flourouracil or ftorafur and X rays. Int J Radiat Oncol Biol Phys 8: $1923-1933$

Cammà C, Giunta M, Fiorica F, Pagliaro L, Craxì A, Cottone M (2000) Preoperative radiotherapy for resectable rectal cancer: a meta-analysis. JAMA 284: 1008 - 1015

Chen AY, Choy H, Rothenberg ML (1999) DNA topoisomerase I-targeting drugs as radiation sensitizers. Oncology 13: 39-46

Colorectal Cancer Collaborative Group (2001) Adjuvant radiotherapy for rectal cancer: a systematic overview of 8507 patients from 22 randomised trials. Lancet 358: $1291-1304$

Douillard JY, Cunningham D, Roth AD, Navarro M, James RD, Karasek P, Jandik P, Iveson T, Carmichael J, Alakl M, Gruia G, Awad L, Rougier P (2000) Irinotecan combined with fluorouracil compared with fluorouracil alone as first-line treatment for metastatic colorectal cancer: a multicentre randomised trial. Lancet 355: $1041-1047$

Enker WE, Thaler HT, Cranor ML, Polyak T (1995) Total mesorectal excision in the operative treatment of carcinoma of the rectum. J Am Coll Surg 181: $335-346$

Falk SJ, Smith PJ (1992) DNA damaging and cell cycle effects of topoisomerase I poison camptothecin in irradiated human cells. Int $J$ Radiation Biol 61: 749-757

Frykholm GJ, Pahlman L, Glimelius B (2001) Combined chemo- and radiotherapy $v s$ radiotherapy alone in the treatment of primary, nonresectable adenocarcinoma of the rectum. Int J Radiat Oncol Biol Phys 50: $427-434$

Gerard J, Bonnetain F, Conroy T, Chapet O, Bouche O, Closon-Dejardin MT, Untereiner M, Leduc B, Francois E, Bedenne L (2005) Preoperative (preop) radiotherapy (RT) $+5 \mathrm{FU} /$ folinic acid (FA) in T3-4 rectal cancers: results of the FFCD 9203 randomized trial. Proc Am Soc Clin Oncol 23: 16S (abstract 3504)

Gollins SW, Myint S, Levine E, Bishop J, Haylock B, Susnerwala S, Saunders M, Biswas A (2006) Radiotherapy plus concurrent irinotecan (CPT-11) and capecitabine (CAP) as preoperative downstaging treatment for locally advanced inoperable rectal cancer: A phase I/II study. Proc Am Soc Clin Oncol 24: 18S (abstract 13519)

Gollins SW, Myint S, Levine E, Morris J, Haylock B, Susnerwala S, Saunders M, Biswas A (2005) Phase I study of radiotherapy (RT) plus concurrent irinotecan (CPT-11) and capecitabine (CAP) as preoperative down- staging treatment for locally advanced inoperable rectal cancer. Proc Am Soc Clin Oncol 23: 16S (abstract 3565)

Hartley A, Ho KF, McConkey C, Geh JI (2005) Pathological complete response following preoperative chemoradiotherapy in rectal cancer analysis of phase II/III trials. Br J Radiol 78: 934-938

Heald RJ, Moran BJ, Ryall RD, Sexton R, MacFarlane JK (1998) Rectal cancer: the Basingstoke experience of total mesorectal excision, 19781997. Arch Surg 133: $894-899$

Hofheinz R-D, Gerstenberg-Helldorf B, Wenz F, Gnad U, Kraus-Tiefenbacher U, Muldner A, Hehlmann R, Post S, Hochhaus A, Willeke F (2005) Phase I Trial of capecitabine and weekly irinotecan in combination with radiotherapy for neoadjuvant therapy of rectal cancer. J Clin Oncol 23: $1350-1357$

Kapiteijn E, Marijnen CA, Nagtegaal ID, Putter H, Steup WH, Wiggers T, Rutten HJ, Pahlman L, Glimelius B, van Krieken JH, Leer JW, van de Velde CJ, for the Dutch Colorectal Cancer Group (2001) Preoperative radiotherapy combined with total mesorectal excision for resectable rectal cancer. $N$ Engl J Med 345: 638-646

Kennedy AS, Kwok Y, Batko-Yovino S, Van Echo DA (2004) A phase I study of preoperative capecitabine, irinotecan concurrent with radiation therapy for resectable rectal cancer. Proc Am Soc Clin Oncol GI Symposium (abstract 268)

Kim C, Anne PR, Mitchell E, Pequignot E, Palazzo J, Goldstein S, Isenberg G, Curran Jr W (2005) Impact of pretreatment size and lymph nodes on pathological complete response and survival in a prospective trial of chemoradiation. Int J Radiat Oncol Biol Phys 63(2 Suppl): S164 (abstract 1034)

Kirichenko AV, Rich TA (1999) Radiation enhancement by a minor camptothesin. The effect of fractionation and timing of administration. Int J Radiat Oncol Biol Phys 44: 659-664

Kirichenko AV, Rich TA, Newman RA, Travis EL (1997) Potentiation of murine $\mathrm{MCa}-4$ carcinoma radioresponse by 9 -amino-20s camptothecin. Cancer Res 57: 1929- 1933

Klautke G, Feyerhead P, Ludwig K, Prall F, Foitzik T, Fietkau R (2005) Intensified concurrent chemoradiotherapy with 5-fluorouracil and irinotecan as neoadjuvant treatment in patients with locally advanced rectal cancer. Br J Cancer 92: 1215-1220

Klautke G, Foitzik T, Ludwig K, Klar EJM, Fietkau R (2004) Intensified neoadjuvant chemoradiotherapy (CRT) with capecitabine and irinotecan in patients with locally advanced rectal cancer (LARC): a phase I/II study. Proc Am Soc Clin Oncol 22: 14S (abstract 3693)

Klautke G, Kuchenmeister U, Foitzik T, Ludwig K, Prall F, Klar E, Fietkau R (2006a) Concurrent chemoradiation with capectitabine and weekly irinotecan as preoperative treatment for rectal cancer: results from a phase I/II study. Br J Cancer 94: 976-981

Klautke G, Ludwig K, Klar E, Freund M, Fietkau R (2006b) Toxicity and efficacy of four schedules of intensified neoadjuvant chemoradiotherapy (RCT) with irinotecan and $5-\mathrm{Fu}$ or capectitabine in patients with locally advanced rectal cancer. Proc Am Soc Clin Oncol 24: 18S (abstract 13550)

Levine EL, Gollins S, Susnerwala S, Haylock B, Saunders M, Myint S, Biswas A (2003) Phase I/II study of irinotecan (CPT11) 5-flourouracil and concurrent radiotherapy in the treatment of T3-T4 locally advanced inoperable rectal cancer. Proc Am Soc Clin Oncol Onc 22 (abstract 1384) p 345

Mawdsley S, Glynne-Jones R, Grainger J, Richman P, Makris A, Harrison M, Ashford R, Harrison RA, Osborne M, Livingstone JI, MacDonald P, Mitchell IC, Meyrick-Thomas J, Northover JM, Windsor A, Novell R, Wallace M (2005) Can histopathologic assessment of circumferential margin after preoperative pelvic chemoradiotherapy for T3-T4 rectal cancer predict for 3 year disease-free survival. Int J Radiat Oncol Biol Phys 63: $745-752$

Mehta VK, Cho C, Ford JM, Jambalos C, Poen J, Koong A, Lin A, Bastidas JA, Young H, Dunphy EP, Fisher G (2003) Phase II trial of preoperative 3D conformal radiotherapy, protracted venous infusion 5-fluorouracil 
and weekly CPT-11, followed by surgery for ultrasound staged T3 rectal cancer. Int J Radiat Oncol Biol Phys 55: $132-137$

Mitchell EP, Anne P, Fry R, Ahmed N, Boman B, Edmunston T, Rakinic J, Goldstein S, Rose L, Palazzo J, Cagir B, Kovatich A, Hauck W, Fishel R, Bonanni R, Hoey R, Rose D, Currani W, Jefferson T (2001) Combined modality therapy of locally advanced or recurrent adenocarcinoma of the rectum: report of a phase I trial of chemotherapy (CT) with CPT 11, $5 \mathrm{FU}$ and concomitant irradiation (RT). Proc Am Soc Clin Oncol 20: 131a (abstract 519)

Mitchell EP, Anne P, Goldstein S, Isenbergn G, Fitzgerald J, Palazzo J, Hauck W, Lavarino J, Sanson J, Curran W (2006) Combined modality therapy of locally advanced adenocarcinoma of the rectum: update of a phase I trial of preoperative radiation (RT) with concurrent capecitabine (Cap) and irinotecan (Ir). Pro Am Soc Clin Oncol 24: 18S (abstract 13547) $619 \mathrm{~S}$

Mitchell EP, Anne PR, Fry R, Palazzo J, Hauck W, Fishel R, Goldstein S, Isenberg G, Edmunston T, Curran W (2003) Chemoradiation with CPT $11,5 \mathrm{FU}$ in neoadjuvant treatment of locally advanced or recurrent adenocarcinoma of the rectum: a phase I/II study update. Proc Am Soc Clin Oncol 22 (abstract 1052) p 262

Nagtegaal ID, Marijnen CA, Kranenbarg EK, Van de Velde CJ, Van Krieken $\mathrm{JH}$, Pathology Review Committee; Cooperative Clinical Investigators (2002) Circumferential margin involvement is still an importan predictor of local recurrence in rectal cancer: not 1 millimetre but 2 millimetres is the limit. Am J Surg Pathol 26: 350-357

Navarro M, Dotor E, Rivera F, Sanchez-Rovira P, Garcia JL, Vega-Villegas ME, Cervantes A, Garcia JL, Gallen M, Aranda E (2006) A phase II study of preoperative radiotherapy and concomitant weekly irinotecan in combination with protracted venous infusion 5-flourouracil, for resectable locally advanced rectal cancer. Int J Radiat Oncol Biol Phys 66: $201-205$

Omura M, Torigoe S, Qubota N (1997) SN38, a metabolite of the camptothecin derivative CPT11 potentiates the cytotoxic effects of radiation in human colon adenocarcinoma cells grown as spheroids. Radiother Oncol 43: 197-208

Quirke P, Durdey P, Dixon MF, Williams NS (1986) Local recurrence of rectal adenocarcinoma due to inadequate surgical resection. Histopathological study of lateral tumour spread and surgical excision. Lancet 2: 996- 999
Rodel C, Grabenbauer GG, Papdopoulos T, Hohenberger W, Scholl HJ, Sauer R (2003) Phase I/II trial of capecitabine, oxaliplatin and radiation for rectal cancer. J Clin Oncol 21: 3098-3104

Saltz LB, Cox JV, Blanke C, Rosen LS, Fehrenbacher L, Moore MJ, Maroun JA, Ackland SP, Locker PK, Pirotta N, Elfring GL, Miller LL (2000) Irinotecan plus fluorouracil and leucovorin for metastatic colorectal cancer. Irinotecan Study Group. N Engl J Med 343: $905-914$

Sauer R, Becker H, Hohenberger W, Rödel C, Wittekind C, Fietkau R, Martus P, Tschmelitsch J, Hager E, Hess CF, Karstens JH, Liersch T, Schmidberger H, Raab R, for the German Rectal Cancer Study Group (2004) Preoperative versus postoperative chemoradiotherapy for rectal cancer. N Engl J Med 351: 1731 - 1740

Sebag-Montefiore D, Glynne-Jones R, Mortensen N, Bedi C, Wilson C, Geh I, McDonald A (2005) Pooled analysis of outcome measures including the histopathological $\mathrm{R} 0$ resection rate after pre-operative chemoradiation for locally advanced rectal cancer. Colorectal disease 7(Suppl 1): (abstract $\mathrm{O} 20 \mathrm{p} \mathrm{7)}$

Swedish Rectal Cancer Trial (1997) Improved survival with preoperative radiotherapy in resectable rectal cancer. $N$ Engl J Med 336: 980 -987

Tamura K, Takada M, Kawase I, Tada T, Kudoh S, Okishio K, Fukuoka MN, Fuliwara Y, Yamakido M (1997) Enhancement of tumor radio-response by irinotecan in human lung tumor xenografts. Jpn J Cancer Res 88: 218-223

Wang DS, Ueno Y, Oyamada H, Kojima S (1996) Enhancement of the antitumour effect of gamma-ray irradiation in combination with camptothecin against human colorectal adenocarcinoma. Biol Pharm Bull 19: 354-359

Wheeler JM, Dodds E, Warren BF, Cunningham C, George BD, Jones AC, Mortenson NJ (2004) Preoperative chemoradiotherapy and total mesorectal excision surgery for locally advanced rectal cancer: correlation with rectal cancer regression grade. Dis Colon Rectum 47: 2025-2031

Wibe A, Rendedal PR, Svensson E, Norstein J, Eide TJ, Myrvold HE, Soreide $\mathrm{O}$ (2002) Prognostic significance of the circumferential resection margin following total mesorectal excision for rectal cancer. Br J Surg 89: 1067

Willeke F, Tiefenbacher U, Hochhaus A, Wenz F, von Gerstenbergk B, Gnad-Vogt U, Horisberger K, Post S, Hofheinz R (2005) Phase II trial of capecitabine and irinotecan in combination with concurrent radiotherapy for neoadjuvant treatment of locally advanced rectal cancer. Pro Am Soc Clin Oncol 23: 16S (abstract 3589) 